\title{
EXPERIMENTAL RICKETS.
}

\author{
By PETER M. HOLST, M.D. \\ From the Hygienic Institute of the University of Oslo.
}

(With Plate II.)

IN $1922 \mathrm{I}$ was able to demonstrate that when rats and rabbits are fed upon boiled oats and cabbage, they develop typical rickets (Holst, 1922). Further experiments showed that this result was also obtained when the food was not boiled, and that chickens on the same diet developed a similar condition (Holst, 1924, 1). In 1923 I pointed out that the cabbage was of no importance, and that rats will develop typical rickets on a diet consisting only of oats. This condition could not be explained as caused by lack of vitamins or salts, but must in my opinion be produced by some unknown factor (Holst, 1924, 2). Since that date I have continued these experiments, the results of which will be given below.

Oats do not occupy any exceptional position as a rickets-producer. Exclusive feeding with wheat, rye, barley, maize and yellow peas will produce the same pathological condition.

I have found that if rats are given only oatmeal, wheatmeal, rolled oats or polished rice, they will also develop typical rickets. From the last mentioned fact one must draw the conclusion that the outer layers of the grain are of no importance in producing the disease.

On a diet consisting exclusively of starch the results were different. This diet is inadequate in several respects. In spite of this, rats will live on starch alone for a period longer than is required for the development of rickets. But, whereas feeding with polished rice, as mentioned, will produce typical rickets, feeding with starch alone will only produce osteoporosis. This fact might be explained as the result of starvation, which has a curative effect upon rickets. An addition of casein and lard did not make any difference, however, although the animals gained in weight. At the same time, control experiments demonstrated that neither the casein nor the lard was able to prevent rickets when added to a diet of oats or oatmeal. Under these circumstances one must consider the possibility, that polished rice contains something, which is lost during the manufacturing of starch, and that this unknown factor has a ricketsproducing power. Evidence will now be given, which strongly supports the latter theory.

In order to isolate the rickets-producing substance, oatmeal was boiled with a dilute solution ( 0.5 per cent.) of hydrochloric acid. The mixture was filtered, neutralised with sodium hydrate and given to rats in daily portions corresponding to 15-20 grm. oatmeal. The basal diet consisted of starch. These animals developed typical rickets, although not quite so severely as on a diet of oats alone. 
These experiments show that oats contain a rickets-producing substance, which may be extracted with hydrochloric acid.

As to the nature of the substance, I can as yet add very little. When oats are destroyed by combustion, the ash does not produce rickets when given in addition to rice starch. One must therefore suppose the substance to be of organic nature. It passes through parchment paper in an ordinary dialysator, and is precipitated with alcohol.

According to the theory of McCollum (1922) rickets is caused by lack of vitamin $\mathrm{D}$ in combination with a faulty ratio between the calcium- and phosphorus-salts. If this ratio in McCollum's diets is compared with the corresponding ratios in the cereals, it will be found that these contain comparatively much more phosphorus than McCollum's rickets-diets. In his diet No. 3143 the ratio $\mathrm{Ca}: \mathrm{P}$ is $1: 0 \cdot 2531$, whereas in wheatmeal it is $1: 4 \cdot 6$, and in oatmeal $1: 5 \cdot 7$. By adding calcium to wheatmeal, it is possible to get a diet, which is practically free from vitamin $\mathrm{D}$, and where the ratio $\mathrm{Ca}: \mathrm{P}$ is the same as in diet 3143. According to McCollum's theory this addition ought to aggravate the rickets. But instead of this I found that even an addition of 1 per cent. of calcium lactate produced a marked improvement of the condition. In some experiments an addition of 3 per cent. of this substance prevented the disease. Where the whole grain of oats and maize was used, an addition of 2 per cent. of calcium lactate prevented the disease in all cases. As calcium had the same preventive power as vitamin D in McCollum's $(1921,2)$ experiments, lack of this substance cannot be the one and only cause of rickets produced by feeding with cereals. An addition of 5 per cent. of sodium phosphate had no preventive effect.

Weiske (1895) many years ago produced osteoporosis in rabbits fed entirely upon oats. This condition he explained as the result of acidosis produced by overfeeding with carbohydrates. In order to eradicate any suspicion that the same cause had produced the picture of rickets in my experiments, it must be mentioned that even big doses of sodium bicarbonate did not prevent the disease. Inversely, neither hydrochloric acid ( 1 per cent. solution given to drink), nor the ash from oatmeal, when given in addition to starch, produced rickets.

On account of the experiments which have been described in this paper, I entertain no doubt that cereals are of the very greatest importance in the aetiology of rickets. In 1925 Mellanby (1925) also came to a similar conclusion, and pointed to the rickets-producing effects of the cereals, which he ascribed to some substance, associated with fatty acids. This statement was confirmed one year ago (Mellanby, 1926). It therefore seems that, following different roads we have come to the same result, that in the production of experimental rickets on a diet of cereals, some toxic substance plays an important part.

As to the details of our experiments, there is some disagreement. Whereas Mellanby obtained the substance by saponification of oatmeal with soda and extracting the acidified mixture with petrol ether, this method, in my hands, gave negative results. In his last publication Mellanby states that he is able 
to destroy the substance in oats by a combination of germination and drying, but so far I have been unable to confirm this.

\section{SUMMARY.}

Rickets is produced in rats by feeding exclusively with cereals and yellow peas. Whereas feeding with polished rice results in typical rickets, feeding

Protocols.

Diet (Amount of food eaten, not weighed)

Oats
Maize
Barley
Wheat
Rye
Yellow peas

Wheatmeal

Rolled oats

Polished rice

Rice starch

Wheat starch

Heated casein, 18; Lard, 52; Marmite, 5 ; Orange juice, 5

Oats and $5 \%$ casein

Oats and $20 \%$ casein

Oatmeal and $15 \%$ lard

Rice starch and extract of oatmeal

Wheat starch and extract of wheatmeal Rice starch and dialysed part of extract of oatmeal

Rice starch and non-dialysable part of extract of oatmeal

Rice starch and alcohol precipitate from extract of oatmeal

Rice starch and filtrate from alcohol precipitation of oatmeal extract

Oats and $2 \%$ calcium lactate

Oats and $5 \%$ calcium lactate

Maize and $5 \%$ calcium lactate

Wheatmeal and $1 \%$ calcium lactate

Wheatmeal and $2 \%$ calcium lactate Wheatmeal and $3 \%$ calcium lactate

Wheatmeal and $5 \%$ sodium phosphate $\left(\mathrm{Na}_{3} \mathrm{PO}_{4}\right)$
Dura-

Total Average weight tion of number $\overbrace{}^{2}$ experiof rats Initial Final ment grm. grm. days $34 \cdot 0 \quad 34.5 \quad 28$ $31 \cdot 6 \quad 31 \cdot 9 \quad 25$ $37 \cdot 0 \quad 52 \cdot 0 \quad 61$ $31 \cdot 0 \quad 29 \cdot 0 \quad 27$

$33 \cdot 0 \quad 49 \cdot 0 \quad 55$

$36 \cdot 0 \quad 31 \cdot 0 \quad 31$

$42.9-43 \cdot 0 \quad 31$

23

$34 \cdot 7$

20

$34 \cdot 0 \quad 45 \cdot 0$

$42 \cdot 0$

$40 \cdot 0$

$40 \cdot 5 \quad 28 \cdot 0$

$41 \cdot 0 \quad 30 \cdot 0$

$39 \cdot 7$

$59 \cdot 4$

$44 \cdot 0 \quad 40 \cdot 0$

$45 \cdot 0 \quad 46 \cdot 0$

$39 \cdot 0 \quad 35 \cdot 0$

$41 \cdot 5 \quad 32 \cdot 0$

$\begin{array}{rrrr}4 & 41 \cdot 0 & 32 \cdot 0 & 32 \\ 11 & 40 \cdot 5 & 33 \cdot 0 & 35\end{array}$

$40 \cdot 5$

$33 \cdot 0$

$\begin{array}{llll}11 & 41 \cdot 0 & 30 \cdot 0 & 27 \\ 28 & 40 \cdot 0 & 29 \cdot 5 & 33\end{array}$

$\begin{array}{llll}8 & 36 \cdot 0 & 31 \cdot 5 & 35\end{array}$

$\begin{array}{llll}4 & 28.0 & 41.0 & 43\end{array}$

$51 \cdot 0$

$\begin{array}{llll}8 & 40 \cdot 0 & 54 \cdot 0 & 51 \\ 4 & 39 \cdot 0 & 35 \cdot 5 & 34\end{array}$

$\begin{array}{llll}4 & 39 \cdot 0 & 35 \cdot 5 & 34\end{array}$

$\begin{array}{llll}2 & 33 \cdot 0 & 37 \cdot 0 & 23\end{array}$

$\begin{array}{llll}4 & 36 \cdot 0 & \mathbf{4 5} \cdot 0 & \mathbf{3 4}\end{array}$

15

$36 \cdot 0$

$35 \cdot 0$

\author{
Result \\ (All animals examined \\ microscopically)
}

All animals showed marked rickets

$\begin{array}{cll}", & " & " \\ " & " & " \\ \text { Twenty-three } & \text { animals } & \text { "showed }\end{array}$

Twenty-three animals showed
marked rickets. One animal died after 9 days without showing rickets

Twenty-two animals showed marked rickets. One animal died after 7 days without showing rickets

All animals showed marked rickets

All animals showed osteoporosis, but no signs of rickets

", " "

All animals showed marked rickets

Thirteen animals" showed "marked rickets. One animal died after 7 , one after 26 and one after 39 days without showing rickets

All animals showed marked rickets

Eight animals showed marked rickets. One animal died after 29 , one after 44 and one after 49 days without showing rickets

All animals showed osteoporosis, but no signs of rickets

Fourteen animals showed marked rickets. Fourteen animals died after 26 to 45 days showing no signs of rickets

All animals showed osteoporosis, but no signs of rickets

No rickets

",

Two" animals showed marked rickets, one traces of rickets and one no rickets

Traces of osteoid

Two animals showed marked rickets, two no rickets

All animals showed marked rickets 
with rice-starch alone will only produce osteoporosis. This difference is not attributable to nitrogen starvation.

If oatmeal is extracted with hydrochloric acid and the extract is given in addition to the starch, the animals develop rickets. The rickets-producing factor of oatmeal must therefore be ascribed to some toxic substance. Evidence is given to show that this substance can pass through parchment-paper and that it can be precipitated with alcohol. Rickets produced by feeding with cereals can be prevented by the administration of calcium-salts, whereas phosphates have no such effect.

\section{REFERENCES.}

Holst, P. M. (1922). Om vitaminer og tran. Forhandl. i Norsk Med. Selskap, Sept. 9th.

- (1924a). Om mangel paa vitamin A og rakit. Norsk Magazin for Laegevidenskaben, p. 933.

— $(1924 b)$. Experimental Rickets. Forhandl. ved Ellevte Nordiske Kongres for Indre Medicin $i$ Kristiania, 1923.

McCollum, E. V., Simmonds, N., Parsons, H. T., Shipley, P. G. and Park, E. A. (1921 a). Studies on Experimental Rickets. I. The Production of Rachitis and Similar Diseases in the Rat by Deficient Diets. J. Biol. Chem. 45, 333.

McCollum, E. V., Simmonds, N., Shipley, P. G. and Park, E. A. (1922). Studies on Experimental Rickets. XXII. Conditions which must be fulfilled in preparing animals for testing the antirachitic effect of individual foodstuffs. Bull. Johns Hopkins Hospital, 33, 296.

Mellanby, E. (1925). Experimental Rickets. Medical Research Council Special Report Series No. 93. London.

- (1926). The Presence in Foodstuffs of Substances having Specific Harmful Effects under Certain Conditions. Proc. Physiol. Soc. March 20th, 1926, J. Physiol. 61.

Shipley, P. G., Park, E. A., McCollum, E. V., Simmonds, N. and Parsons, H. T. (1921 $b)$. Studies on Experimental Rickets. II. The Effect of Cod Liver Oil administered to Rats with Experimental Rickets. J. Biol. Chem. 45, 343.

Wriske (1895). Versuche über die Wirkung einer Beigabe von Calcium-, Strontium- resp. Magnesiumcarbonat zu einem kalkarmen aber phosphorsäurereichen Futter auf den thierischen Organismus, insbesondere auf die Zusammensetzung des Skelettes. Zeitschr. f. Biol. 31, 421.

\section{EXPLANATION OF PLATE II.}

Fig. 1. Epiphysis of tibia, rat, fed only on oats. Rickets.

Fig. 2. Rib junction of rat, fed only on polished rice. Rickets.

Fig. 3. Epiphysis of tibia, rat, fed only on polished rice. Rickets.

Fig. 4. Rib junction of rat, fed only on rice starch. Osteoporosis.

Fig. 5. Epiphysis of femur, rat, fed only on rice starch. Osteoporosis.

Fig. 6. Rib junction of rat, fed only on rice starch and extract of oatmeal. Rickets.

Fig. 7. Epiphysis of tibia, rat, fed only on rice starch and extract of oatmeal. Rickets.

Fig. 8. Epiphysis of tibia, rat, fed only on oats and 2 per cent. calcium lactate. Normal. Lettering: $c=$ cartilage; $c a=$ calcified bone tissue; $o=$ ostoid tissue.

(MS. received ca. 16. Iv. 1927.-Ed.) 
JOURNAL OF HYGIENE, VOL. XXVI. NO. 4

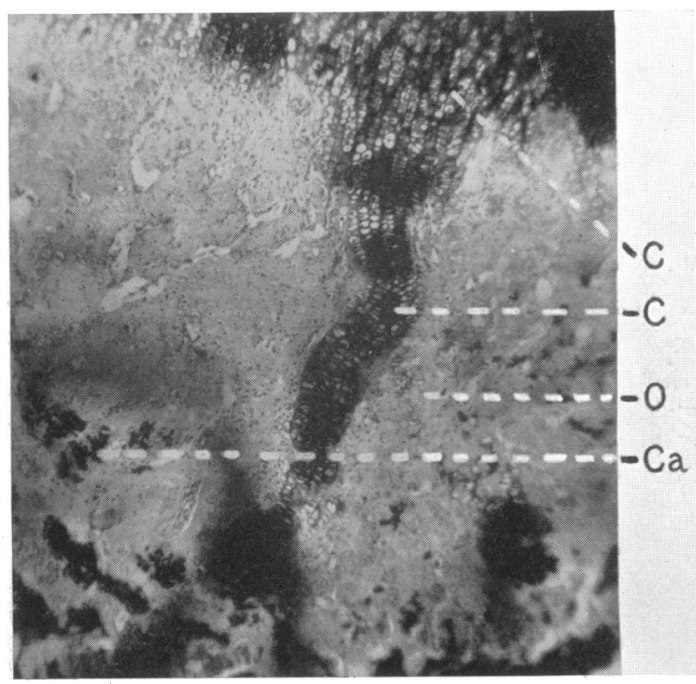

Fig. 1

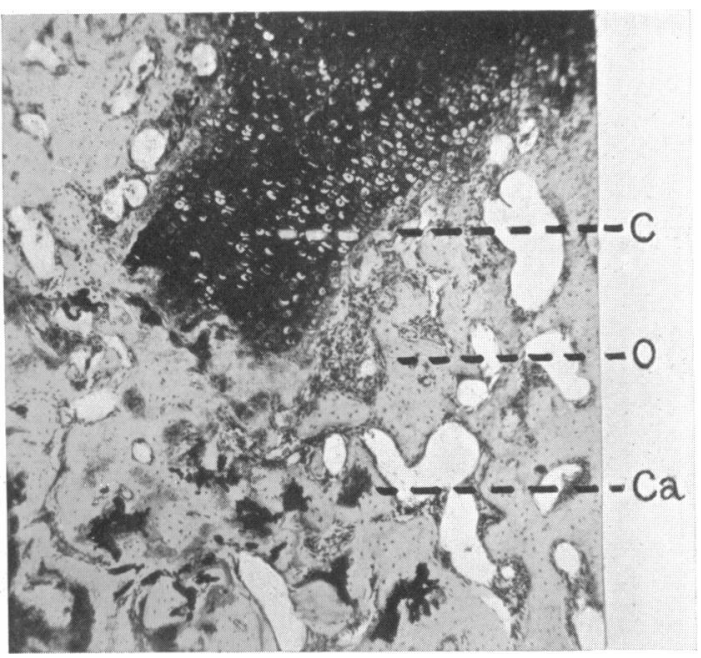

Fig. 3

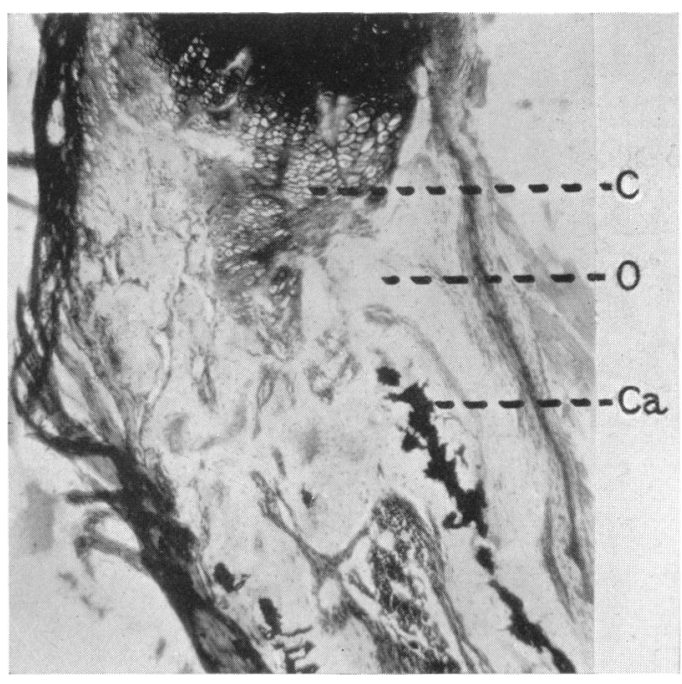

Fig. 2

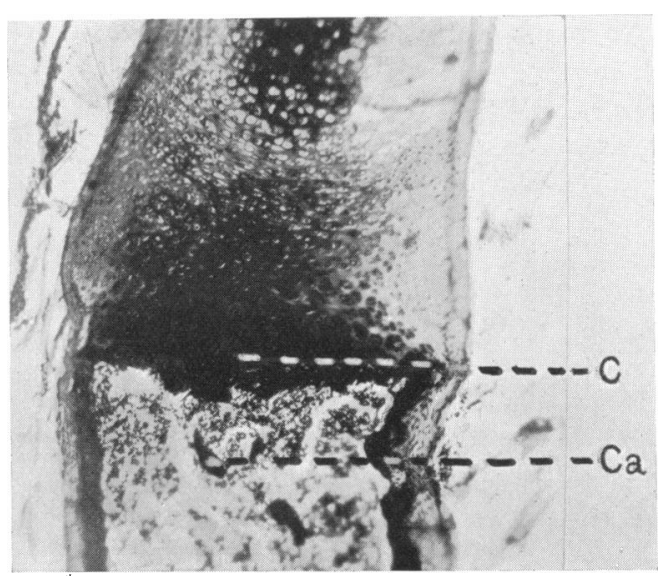

Fig. 4 
PLATE II

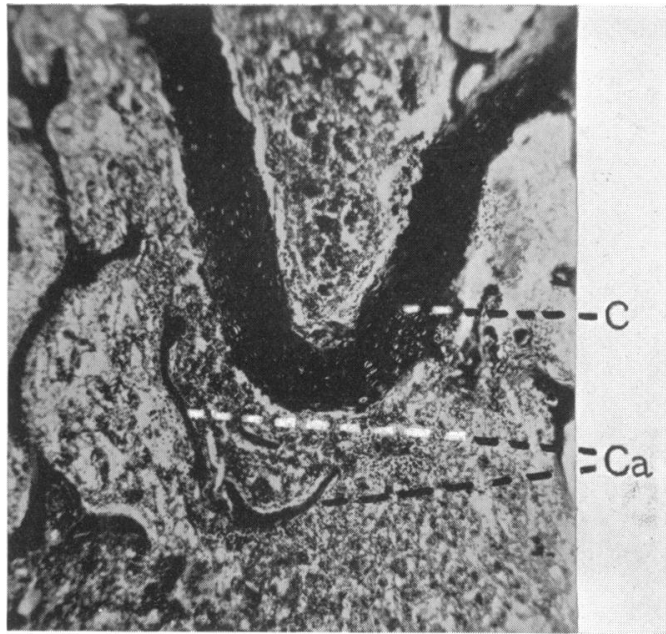

Fig. 5

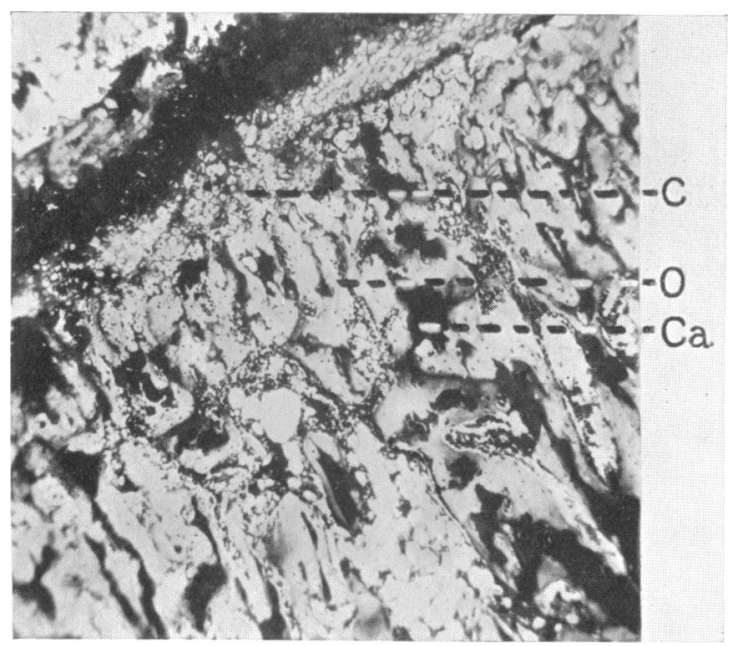

Fig. 7

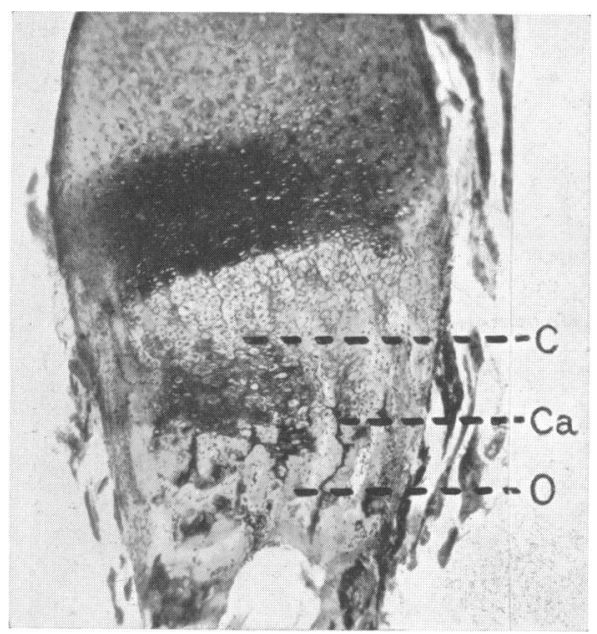

Fig. 6

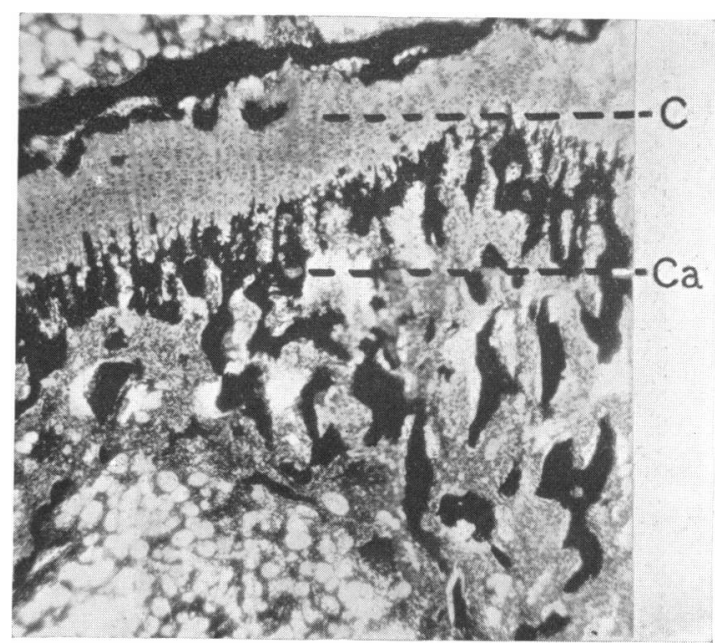

Fig. 8 